\title{
Serum lipid profile and its association with hypertension in Bangladesh
}

\author{
This article was published in the following Dove Press journal: \\ Vascular Health and Risk Management \\ 30 June 2014 \\ Number of times this article has been viewed
}

\author{
Kamrun Nahar Choudhury' \\ AKM Mainuddin ${ }^{2}$ \\ Mohammad Wahiduzzaman ${ }^{3}$ \\ Sheikh Mohammed Shariful \\ Islam ${ }^{4,5}$ \\ 'Department of Epidemiology, \\ National Centre for Control of \\ Rheumatic Fever and Heart Disease, \\ ${ }^{2}$ Center for Communicable Diseases, \\ International Center for Diarrheal \\ Disease Research, ${ }^{3}$ Department of \\ Cardiology, Bangladesh Institute of \\ Health Science, Bangladesh, Dhaka, \\ Bangladesh; ${ }^{4}$ Center for Control \\ of Chronic Diseases, International \\ Center for Diarrheal Disease \\ Research, Bangladesh, Dhaka, \\ Bangladesh; ${ }^{5}$ Center for International \\ Health, University of Munich, Munich, \\ Germany
}

Background: Hypertension and dyslipidemia are major risk factors for cardiovascular disease, accounting for the highest morbidity and mortality among the Bangladeshi population. The objective of this study was to determine the association between serum lipid profiles in hypertensive patients with normotensive control subjects in Bangladesh.

Methods: A cross-sectional study was carried out among 234 participants including 159 hypertensive patients and 75 normotensive controls from January to December 2012 in the National Centre for Control of Rheumatic Fever and Heart Disease in Dhaka, Bangladesh. Data were collected on sociodemographic factors, anthropometric measurements, blood pressure, and lipid profile including total cholesterol (TC), triglyceride (TG), low density lipoprotein (LDL), and high density lipoprotein (HDL).

Results: The mean ( \pm standard deviation) systolic blood pressure and diastolic blood pressure of the participants were $137.94 \pm 9.58$ and $94.42 \pm 8.81$, respectively, which were higher in the hypertensive patients $(P<0.001)$. The serum levels of TC, TG, and LDL were higher while HDL levels were lower in hypertensive subjects compared to normotensives, which was statistically significant $(P<0.001)$. Age, waist circumference, and body mass index showed significant association with hypertensive patients $(P<0.001)$ but not with normotensives. The logistic regression analysis showed that hypertensive patients had 1.1 times higher TC and TG, 1.2 times higher LDL, and 1.1 times lower HDL than normotensives, which was statistically significant $(P<0.05)$.

Conclusion: Hypertensive patients in Bangladesh have a close association with dyslipidemia and need measurement of blood pressure and lipid profile at regular intervals to prevent cardiovascular disease, stroke, and other comorbidities.

Keywords: Risk factors, cardiovascular diseases, dyslipidemia, blood pressure

\section{Introduction}

Hypertension and dyslipidemia are major risk factors for cardiovascular disease (CVD) and account for more than $80 \%$ of deaths and disability in low- and middleincome countries. ${ }^{1,2}$ The prevalence of hypertension is projected to increase globally, especially in the developing countries. ${ }^{2}$ In recent years, rapid urbanization, increased life expectancy, unhealthy diet, and lifestyle changes have led to an increased rate of CVD in Southeast Asia, including Bangladesh. ${ }^{3}$ It is widely accepted that CVD is associated with hypertension and increased blood levels of low-density lipoprotein (LDL), total cholesterol (TC), and triglycerides (TG). In contrast, a low level of high density lipoprotein (HDL) is a risk factor for mortality from CVD. ${ }^{4}$ Epidemiological studies have established a strong association between hypertension and coronary artery disease..$^{5}$
Correspondence: Sheikh Mohammed Shariful Islam

Center for Control of Chronic Diseases, International Center for Diarrheal Disease Research, Bangladesh, 68, Shaheed Tajuddin Ahmed Sarani, Mohakhali, Dhaka I212, Bangladesh Tel +8802 I939366930

Email shariful.islam@icddrb.org 
The noncommunicable disease risk factor survey conducted in 2010 in Bangladesh estimated the prevalence of hypertension among adults to be from $16 \%$ to $20 \%{ }^{6}$ The Bangladesh Health, Nutrition and Demographic Survey in 2011 found the prevalence of hypertension among adults to be $34 \%{ }^{7,8}$ A meta-analysis of the prevalence of hypertension in Bangladesh from 1995 to 2009 among 6,430 adults was estimated to be $13.5 \%$, with a $95 \%$ confidence interval (CI) ranging from $12.7 \%$ to $14.2 \% .{ }^{6}$ Another meta-analysis of prevalence of CVD and type 2 diabetes between 1995 and 2010 found the pooled prevalence of hypertension to be $13.7 \%$ (12.1\%-15.3\%), with an increasing trend and higher rate in urban areas versus rural $(22.2 \%$ versus $14.3 \%$, respectively). ${ }^{9}$ However, these numbers are estimated from several studies and are likely not to account for silent and other asymptomatic CVD and hypertension.

CVD is the leading cause of disability and death worldwide, and a great majority of CVDs are associated with dyslipidemia. Worldwide, there is broad variation in serum lipid profile levels among different population groups. Increased serum levels of TC, TG, LDL, and decreased HDL are known to be associated with major risk factors for CVD. Dyslipidemia, comprising altered ratio of high TC level and isolated evaluation of the LDL or TG, is usually associated with increased blood pressure (BP) levels. There is a strong relationship between total LDL cholesterol concentrations and CVD risk. Patterns of lipid abnormalities among Asians and their relative impact on cardiovascular risk have not been well characterized. ${ }^{10}$ Low HDL is increasingly recognized as an independent risk factor for adverse CVD outcomes, irrespective of levels of LDL. Although sporadic reports suggest that the prevalence of low HDL-cholesterol is substantial, we lack detailed data on the true prevalence of this condition among patients receiving treatment for dyslipidemia. ${ }^{11}$ These data strongly suggest that low HDL is a clinically significant problem.

In Bangladesh, consumption of saturated fat and red meat is a known risk factor for CVD, especially hypertension. ${ }^{12}$ However, data about the relationship between hypertension and lipid profile among Bangladeshi patients are rare in the literature. The purpose of the study was to compare the blood lipid levels in hypertensive patients with normotensive control subjects and determine its association between hypertension and lipid profile.

\section{Materials and methods Study design and population}

A cross sectional study was conducted among 234 participants, 159 newly diagnosed hypertensive patients and 75 participants with normal BP (normotensives), attending the National Centre for Control of Rheumatic Fever and Heart Disease (NCCRF\&HD) in Dhaka, Bangladesh for a routine health check-up between January and December 2012. All the participants were residents of surrounding areas in Dhaka and aged between 30-60 years. Participants were selected consecutively from the outpatient department by the attending physician. Patients with features of any cardiac, renal, or hepatic complications or major medical problems were excluded. Also, those on lipid lowering and antihypertensive medication were also excluded. After obtaining oral and written informed consent, data was collected through face-to-face interviews, anthropometric measurements, clinical examinations, and blood tests for serum lipid profile by trained research assistants.

\section{Measurements}

Height and body weight were measured with participants standing without shoes and heavy outer garments. Body mass index (BMI) was calculated as weight in kilograms, divided by height in meters squared $\left(\mathrm{kg} / \mathrm{m}^{2}\right)$. Waist circumference (WC) was measured from midway between the lowest rib and the iliac crest using a Gullick II tape with subjects in the standing position and at the end of a normal expiration. Two measurements were taken from each subject, and the mean value was used for the analysis. All anthropometric measurements were collected by the same individual.

$\mathrm{BP}$ was measured by a physician using standard BP measurement protocol after the patient had rested for 10 minutes. Two measurements were taken by a mercury sphygmomanometer, with at least a 5-minute interval between successive measurements. The mean of two measurements of Korotkoff phase I was recorded for systolic blood pressure (SBP). The mean of two values of Korotkoff phase IV was recorded for diastolic blood pressure (DBP). Hypertension was defined as an average $\mathrm{SBP} \geq 140 \mathrm{mmHg}$ and $\mathrm{DBP} \geq 90 \mathrm{mmHg}$ without antihypertensive medication according to the seventh report of the Joint National Committee on Prevention, Detection, Evaluation and Treatment of High Blood Pressure (JNC-7). ${ }^{13}$ In this study, hypertensive patients refer to those participants who demonstrated the JNC-7 criteria.

\section{Biochemical analysis}

A volume of $5 \mathrm{~mL}$ of venous blood was collected in the morning after an overnight fast, and serum was used for biochemical tests. All tests were carried out at the laboratory of the NCCRF\&HD in Dhaka, Bangladesh. Lipid parameters (TC, TG, LDL, and HDL) were estimated by enzymatic colorimetric methods. Dyslipidemia was defined 
according to the Evaluation and Treatment of High Blood Cholesterol in Adults executive summary of the third report of the National Cholesterol Education Program Expert Panel on Detection, Evaluation and Treatment of High Blood Cholesterol in Adults (Adult Treatment Panel III): LDL cholesterol $(\mathrm{mg} / \mathrm{dl})<100=$ optimal, $100-129=$ near optimal $/$ above optimal, 130-159=borderline high, 160-189= high, $\geq 190=$ very high; total cholesterol $(\mathrm{mg} / \mathrm{dl})<200=$ desirable, 200-239= borderline high, $\geq 240=$ very high; HDL cholesterol $(\mathrm{mg} / \mathrm{dl})<40=$ low, $\geq 60=$ high; triglyceride $(\mathrm{mg} / \mathrm{dl})<150=$ normal (goal), 150-199= borderline high, 200-499= high, $\geq 500=$ very high. ${ }^{14}$

\section{Ethics}

Ethical clearance was obtained from the NCCRF\&HD. Participants were informed about the study, and both verbal and written informed consent was obtained. The Helsinki Declaration was strictly followed for data collection. ${ }^{15}$

\section{Data analysis}

Data were analyzed using Statistical Package for Social Sciences software, version 16.0 (SPSS Inc., Chicago, IL, USA). Descriptive statistics was used to present the demographic characteristics of the study participants. Continuous variables were presented as mean \pm standard deviation (SD) and were compared using independent group Student's $t$-tests. Binary logistic regression analysis was performed to measure the relationship of lipid profile among the hypertensive and normotensive patients after adjusting for age, BMI, sex, and BP. A $P$-value $<0.05$ was considered statistically significant.

\section{Results}

The study included 234 participants with a mean age \pm SD of $44.7 \pm 5.7$ years and BMI of $25.2 \pm 3.8 \mathrm{~kg} / \mathrm{m}^{2}$. The mean SBP and DBP were 137.9 $\pm 9.6 \mathrm{mmHg}$ and $94.4 \pm 8.8 \mathrm{mmHg}$, respectively. The mean BMI, TC, HDL, and LDL were higher for males compared to females, which was statistically significant $(P<0.05)$. The mean WC was higher in males, which was not statistically significant $(P=0.051)$ (Table 1$)$.

The mean age \pm SD of hypertensive patients and normotensives were $47.6 \pm 4.2$ and $38.4 \pm 3.7$ years, respectively. Serum levels of TC, TG, and LDL were $238.3 \pm 3.4,178.3 \pm 6.3$, and $151.3 \pm 7.8 \mathrm{mg} / \mathrm{dL}$, respectively, in hypertensive subjects while in normotensive subjects, they were $187 \pm 6.2$, $141.5 \pm 11.2$, and $110.3 \pm 6.3 \mathrm{mg} / \mathrm{dL}$, respectively, which were significantly higher in hypertensive patients $(P<0.001)$. The serum HDL was significantly lower $(P<0.001)$ in hypertensive patients $(41.2 \pm 3.2 \mathrm{mg} / \mathrm{dL})$ than in normotensive subjects
$(44.3 \pm 5.6 \mathrm{mg} / \mathrm{dL})$. The mean SBPs of hypertensives and normotensives were $146.8 \pm 8.5 \mathrm{mmHg}$ versus $119.2 \pm 9.3$ $\mathrm{mmHg}$, respectively, and mean DBPs were $98.9 \pm 7.3 \mathrm{mmHg}$ versus $84.9 \pm 5.3 \mathrm{mmHg}$, respectively. The mean $\mathrm{SBP}$ and DBP of hypertensives were higher than those of normotensives $(P<0.001)$. Age, $\mathrm{WC}$, and $\mathrm{BMI}$ showed significant association with hypertensive patients $(P<0.001)$ but not with normotensive subjects (Table 2).

Binary logistic regression analysis showed TC was significantly associated with hypertensive patients and the odds ratio (OR) was $1.1,95 \%$ CI $0.91-1.77, P<0.002$. TG and LDL were significantly associated with hypertensive patients (OR 1.1, 95\% CI 0.49-1.44, $P<0.05$ and OR $1.2,95 \%$ CI $0.69-1.66, P<0.001$, respectively). HDL was also associated with hypertensive patients (OR 1.08, 95\% CI $0.77-1.52, P<0.05)$. DBP showed significant association with hypertensive patients (OR 1.7, 95\% CI 0.33-3.29, $P<0.05$ ) (Table 3).

\section{Discussion}

In this study, we investigated the relationship between serum lipid profile and hypertension among an urban population in Bangladesh. Results of this study revealed that the mean values of serum TC, TG, and LDL were significantly higher and statistically significant among the hypertensive patients compared to normotensives. The mean HDL level was lower in the hypertensives compared to normotensives and was statistically significant.

Hypertension is recognized globally as a major risk factor for CVD, stroke, diabetes, and renal diseases. ${ }^{16}$ About $80 \%$ of hypertensive persons have comorbidities such as obesity, glucose intolerance, abnormalities in lipid metabolism, among others. A prospective study in the northern region of Bangladesh comparing lipid profile status in hypertensive patients as compared to healthy normotensive controls found high serum TC, TG, and LDL, similar to our study. ${ }^{17}$ Our findings of increased levels of TC in hypertensive patients are similar to the findings of some other studies. ${ }^{16,18,19}$ However, few studies measured the strong association of hypertension and dyslipidemia among the Bangladeshi population.

Analysis from the INTERHEART study shows that among both cases and controls, mean LDL levels were about $10 \mathrm{mg} /$ dL lower in Asians compared with non-Asians..$^{10}$ A greater proportion of Asian cases and controls had LDL $\leq 100 \mathrm{mg}$ / dL. HDL levels were slightly lower among Asians compared with non-Asians, a population who require further study and targeted intervention. ${ }^{10}$ Several studies have shown that most of the hypertensive patients undergo inconsistent treatment, 
Table I Characteristics of the respondents

\begin{tabular}{|c|c|c|c|c|c|}
\hline Indicators & $\begin{array}{l}\text { Total }(n=234) \\
\text { mean }(S D)\end{array}$ & Ranges & $\begin{array}{l}\text { Male }(n=128) \\
\text { mean }(S D)\end{array}$ & $\begin{array}{l}\text { Female }(n=106) \\
\text { mean }(S D)\end{array}$ & $P$-value \\
\hline Age (in years) & $44.70(5.7 \mathrm{I})$ & $(38-5 I)$ & $46.21(4.48)$ & $43.19(6.14)$ & 0.278 \\
\hline Height (meter) & $1.55(0.58)$ & $(I-2.03)$ & $1.49(0.49)$ & $\mathrm{I} .6 \mathrm{I}(0.63)$ & 0.061 \\
\hline Education (in years) & $7(3.01)$ & $(0-12)$ & $8(2.99)$ & $6(3.26)$ & 0.872 \\
\hline Weight (kg) & $60.57(7.21)$ & $(4 I-72)$ & $69.21(6.36)$ & $51.93(8.11)$ & 0.074 \\
\hline WC $(\mathrm{cm})$ & $83.53(6.3)$ & $(64-91)$ & $88.89(5.55)$ & $78.17(6.35)$ & 0.051 \\
\hline BMI & $25.2 I(3.8 I)$ & $(2 \mathrm{I}-28)$ & $25.88(3.6 I)$ & $24.54(2.97)$ & 0.022 \\
\hline $\mathrm{SBP}(\mathrm{mmHg})$ & I 37.94 (9.58) & $(107-153)$ & $139.12(11.23)$ & I36.76 (I0.22) & 0.047 \\
\hline DBP (mmHg) & $94.42(8.81)$ & $(86-I I I)$ & 92.14 (7.58) & 96.7 (8.39) & 0.012 \\
\hline Total cholesterol & $221.87(4.14)$ & $(211-229)$ & $224(4.85)$ & $219.74(3.94)$ & 0.032 \\
\hline Triglyceride & I 66.53 (7.38) & $(152-174)$ & I69.2I (6.58) & I63.85 (6.97) & 0.004 \\
\hline $\mathrm{HDL}$ & $42.21(3.68)$ & $(37-46)$ & 46.21 (4.0I) & $38.21(3.33)$ & 0.001 \\
\hline LDL & 138.15 (5.25) & $(131-144)$ & I4I.II (4.69) & $135.19(3.74)$ & 0.014 \\
\hline
\end{tabular}

Abbreviations: BMI, body mass index; DBP, diastolic blood pressure; HDL, high density lipoprotein; LDL, low density lipoprotein; SBP, systolic blood pressure; SD, standard deviation; WC, waist circumference.

Table 2 Anthropometric and biochemical characteristics of participants

\begin{tabular}{|c|c|c|c|c|c|}
\hline \multirow[t]{2}{*}{ Indicators } & \multicolumn{2}{|c|}{ Hypertensive $=159$} & \multicolumn{2}{|c|}{ Normotensive $=75$} & \multirow[t]{2}{*}{$P$-value } \\
\hline & Mean (SD) & $95 \% \mathrm{Cl}$ & Mean (SD) & $95 \% \mathrm{Cl}$ & \\
\hline Age (in years) & $47.67(4.15)$ & $45.48-49.86$ & 38.39 (3.69) & $35.53-41.24$ & 0.001 \\
\hline Height (meter) & $1.55(0.54)$ & $1.53-1.57$ & $1.66(0.59)$ & $1.34-1.73$ & 0.001 \\
\hline Weight (kg) & $62.32(6.33)$ & $60.41-64.23$ & $56.87(7.78)$ & $54.09-59.65$ & 0.001 \\
\hline WC (cm) & 86.01 (5.89) & $84.25-87.76$ & $78.27(6.14)$ & $75.40-81.13$ & 0.001 \\
\hline $\mathrm{BMI}$ & $25.98(3.39)$ & $25.10-26.85$ & $23.58(2.64)$ & $22.58-24.59$ & 0.001 \\
\hline $\mathrm{SBP}(\mathrm{mmHg})$ & | 46.77 (8.5I) & $|4| .|1-15| .42$ & 119.21 (9.3I) & II7.42-23.0I & 0.001 \\
\hline $\mathrm{DBP}(\mathrm{mmHg})$ & $98.92(7.26)$ & $94.49-101.36$ & $84.89(5.29)$ & $81.17-87.61$ & 0.001 \\
\hline Total cholesterol & 238.31 (3.39) & $221.01-242.5$ & I87.0| (6.25) & $\mid 81.52-191.51$ & 0.001 \\
\hline Triglyceride & I $78.34(6.31)$ & $|7| .5|-| 8||$. & |41.48 (I I.29) & |38.82-|43.13 & 0.001 \\
\hline HDL & $41.24(3.22)$ & $39.13-46.35$ & $44.28(5.63)$ & $42.65-49.91$ & 0.001 \\
\hline LDL & I5I.28 (7.77) & $|48.23-| 55.3$ & II0.3I (6.34) & $107.65-1 \mid 4.96$ & 0.001 \\
\hline Male n (\%) & $113(7 \mathrm{I})$ & & $32(42)$ & & $0.002^{*}$ \\
\hline Smoking n (\%) & $57(36)$ & & $16(2 \mid)$ & & $0.258^{*}$ \\
\hline
\end{tabular}

Note: *Represents proportion test.

Abbreviations: BMI, body mass index; CI, confidence interval; DBP, diastolic blood pressure; HDL, high density lipoprotein; LDL, low density lipoprotein; SBP, systolic blood pressure; SD, standard deviation; WC, waist circumference.

Table 3 Binary logistic regression analysis for hypertensive and normotensive participants

\begin{tabular}{llll}
\hline Indicators & $\begin{array}{l}\text { Odds } \\
\text { ratio }\end{array}$ & $\begin{array}{l}\text { Confidence } \\
\text { interval }\end{array}$ & P-value \\
\hline Total cholesterol $(<200 \mathrm{mg} / \mathrm{dL})$ & $\mathrm{I} .12$ & $0.9 I-1.77$ & 0.002 \\
Triglyceride $(<150 \mathrm{mg} / \mathrm{dL})$ & $\mathrm{I} .13$ & $0.49-1.44$ & 0.048 \\
HDL $(60 \mathrm{mg} / \mathrm{dL})$ & 1.08 & $0.77-1.52$ & $0.03 \mathrm{I}$ \\
LDL $(<100 \mathrm{mg} / \mathrm{dL})$ & 1.24 & $0.69-1.66$ & $0.00 \mathrm{I}$ \\
Sex $(\mathrm{male})$ & 0.98 & $0.4 I-1.12$ & $0.22 \mathrm{I}$ \\
SBP $(<140 \mathrm{mmHg})$ & $\mathrm{I} .17$ & $0.78-2.1 \mathrm{I}$ & 0.054 \\
DBP $(<90 \mathrm{mmHg})$ & $\mathrm{I} .74$ & $0.33-3.29$ & 0.044 \\
\hline
\end{tabular}

Abbreviations: DBP, diastolic blood pressure; HDL, high density lipoprotein; LDL, low density lipoprotein; SBP, systolic blood pressure.

and there was significant instability of serum TC, TG, HDL, and LDL in hypertensive patients. ${ }^{19-21}$ Therefore, the findings from investigations of these parameters may reinforce routine monitoring of hypertensive patients in daily clinical practice to prevent CVD and other harmful consequences of hypertension. ${ }^{22}$

A large scale study conducted in Mexico showed that the most prevalent abnormality in Mexican urban adults, aged 20-69 years, was HDL cholesterol below $0.9 \mathrm{mmol} / \mathrm{L}$ ( $46.2 \%$ for men and $28.7 \%$ for women). Hypertriglyceridemia $(>2.26 \mathrm{mmol} / \mathrm{L})$ was the second most prevalent abnormality (24.3\%). Increased LDL $(\geq 4.21 \mathrm{mmol} / \mathrm{L}$ ) was observed in $11.2 \%$ of the sample. Half of the hypertriglyceridemic subjects had a mixed dyslipidemia or low HDL cholesterol. More than $50 \%$ of the low HDL cases were not related to hypertriglyceridemia. ${ }^{23}$ The pan-European Survey of HDL measured lipids and other cardiovascular risk factors in 3,866 patients with type 2 diabetes and 4,436 nondiabetic patients undergoing treatment for dyslipidemia in eleven European 
countries, and showed that diabetic patients had lower HDL $(1.22 \pm 0.37 \mathrm{mmol} / \mathrm{L}$ versus $1.35 \pm 0.44 \mathrm{mmol} / \mathrm{L}, P<0.001)$ and higher TG $(2.32 \pm 2.10 \mathrm{mmol} / \mathrm{L}$ versus $1.85 \pm 1.60$ $\mathrm{mmol} / \mathrm{L}, P<0.001)$ than nondiabetic patients. ${ }^{24}$ More diabetic compared to nondiabetic patients had low HDL (45\% versus $30 \%$, respectively), high TG ( $\geq 1.7 \mathrm{mmol} / \mathrm{L}$; $57 \%$ versus $42 \%$, respectively), or both (32\% versus $19 \%$, respectively). HDL $<0.9 \mathrm{mmol} / \mathrm{L}$ was found in $18 \%$ of diabetic and $12 \%$ of nondiabetic subjects. ${ }^{24}$

Previous studies showed the high rate of CVD mortality among South-East Asian compared to the rest of the world and that majority of CVD deaths occur below the age of $70 .{ }^{25-28} \mathrm{~A}$ wide range of risk factors for CVD has been studied in Bangladesh, but few studies have measured the association of CVD risk with hypertension and lipid profile. A study in rural areas of Bangladesh reported that the prevalence of "high" TC concentration $(>240 \mathrm{mg} / \mathrm{dL}$ or $>6.2 \mathrm{mmol} / \mathrm{L})$ in Bangladesh is about 17\%, "high" LDL ( $\geq 160 \mathrm{mg} / \mathrm{dL}$ or $\geq 4.2 \mathrm{mmol} / \mathrm{L}$ ) is about $2 \%$, and "low" HDL $(<40 \mathrm{mg} / \mathrm{dL}$ or $<1.04 \mathrm{mmol} / \mathrm{L})$ is about $67 \% .^{29}$

\section{Limitations}

Our study has several limitations. First, the sample size was obtained from an urban hospital and may not be representative of all hypertensive patients in Bangladesh. Second, our sample size was small, and the control group was selected purposively, not age and sex matched. In addition, we could not compare the effects of lipid profile variation due to diet, physical activity, medication, or other factors.

\section{Conclusion}

The results of this study demonstrate that patients with hypertension are more likely than normotensive patients to exhibit dyslipidemia, including elevated TC, LDL, TG, and reduced HDL cholesterol levels. Our results suggest that elevated BP may predict certain disturbances in lipoprotein metabolism. This association will help to develop future strategies for preventing both hypertension and dyslipidemia through proper lifestyle changes or medical management or by the combination of both. Hypertensive patients need measurement of BP and lipid profile at regular intervals throughout their primary health care to prevent CVD and stroke.

\section{Acknowledgments}

We express our sincere thanks to all the participants in this study. We also thank all the physicians, pathologists, and staff of the NCCRF\&HD who provided support for this study. We are grateful to Mr SM Majedul Karim, Ludwig-Maximilians University of Munich, Germany for reviewing this manuscript and providing feedback.

\section{Disclosure}

The authors report no conflicts of interest in this work.

\section{References}

1. Reddy KS. Cardiovascular disease in non-Western countries. $N$ Engl J Med. 2004;350(24):2438-2440.

2. Murray CJ, Lopez AD. Global mortality, disability, and the contribution of risk factors: Global Burden of Disease Study. Lancet. 1997; 349(9063): 1436-1442.

3. Joshi P, Islam S, Pais P, et al. Risk factors for early myocardial infarction in South Asians compared with individuals in other countries. JAMA. 2007;297(3):286-294.

4. Mora S, Glynn RJ, Ridker PM. High-density lipoprotein cholesterol, size, particle number, and residual vascular risk after potent statin therapy. Circulation. 2013;128(11):1189-1197.

5. Liu Y, Zhang B, Chen JY, Chen PY. The relationship between fasting triglyceride level and prevalence and severity of angiographic coronary artery disease in 16,650 patients from the TRUST study in the statins era. Eur Heart J. 2013;34(Suppl 1):P1550.

6. Moniruzzamani AT, Rahmani S, Acharyyai A, Islami FA, Ahmedi MSAM, Zamanii MM. Prevalence of hypertension among the Bangladeshi adult population: a meta-analysis. Regional Health Forum, Vol 17, No 1. Geneva: World Health Organization; 2013.

7. Akhtaruzzaman M, Khan MNI, Islam SN. Nutrition, Health and Demographic Survey of Bangladesh-2011. Dhaka, Bangladesh: Institute of Nutrition and Food Science University of Dhaka; 2013. Available from: http://www.du.ac.bd/DownLoads/qlink/nhadsb.pdf. Accessed May 12, 2014

8. World Health Organization. Non-Communicable Disease Risk Factor Survey Bangladesh 2010. Ministry of Health and Family Welfare, Bangladesh; 2010. Available from: http://www.ban.searo.who.int/LinkFiles/Publication_NCD_Risk_Factor_Survey_Report.pdf. Accessed May 12, 2014.

9. Saquib N, Saquib J, Ahmed T, Khanam MA, Cullen MR. Cardiovascular diseases and type 2 diabetes in Bangladesh: a systematic review and meta-analysis of studies between 1995 and 2010. BMC Public Health. 2012;12:434.

10. Karthikeyan G, Teo KK, Islam S, et al. Lipid profile, plasma apolipoproteins, and risk of a first myocardial infarction among Asians: an analysis from the INTERHEART Study. $J$ Am Coll Cardiol. 2009;53(3):244-253.

11. Bruckert E, Pamphile R, McCoy F, André P. Defining the prevalence of low HDL-C in a European cohort of dyslipidaemic patients. Eur Heart J Supplements. 2005;7(Supp1 F):F23-F26.

12. Teo K, Lear S, Islam S, et al; PURE Investigators. Prevalence of a healthy lifestyle among individuals with cardiovascular disease in high-, middle- and low-income countries: The Prospective Urban Rural Epidemiology (PURE) study. JAMA. 2013;309(15):1613-1621.

13. Krousel-Wood M, Muntner P, Carson A, et al. Hypertension control among newly treated patients before and after publication of the main ALLHAT results and JNC 7 guidelines. J Clin Hypertens (Greenwich). 2012;14(5):277-283.

14. National Cholesterol Education Program (NCEP) Expert Panel on Detection, Evaluation, and Treatment of High Blood Cholesterol in Adults (Adult Treatment Panel III). Third report of the National Cholesterol Education Program Expert Panel on detection, evaluation, and treatment of high blood cholesterol in adults (Adult Treatment Panel III) final report. Circulation. 2002;106(25):3143-3421.

15. World Medical Association Declaration of Helsinki: ethical principles for medical research involving human subjects. JAMA. 2000; 284(23):3043-3045. 
16. Saha MS, Sana NK, Shaha RK. Serum lipid profile of hypertensive patients in the northern region of Bangladesh. J Bio-Sci. 2006;14: 93-98.

17. Islam AK, Majumder AA. Hypertension in Bangladesh: a review. Indian Heart J. 2012;64(3):319-323.

18. Anjum R, Zahra N, Rehman K, et al. Comparative Analysis of Serum Lipid Profile between Normotensive and Hypertensive Pakistani Pregnant Women. J Mol Genet Med. 2013;7:64.

19. Bambara R, Mittal Y, Mathur, A. Evaluation of Lipid Profile of North Indian Hypertensive Subjects. Asian Journal of Biomedical and Pharmaceutical Sciences. 2013;3:38-41.

20. Ijeh I, Ejike CE, Okorie U. Serum lipid profile and lipid pro-atherogenic indices of a cohort of Nigerian adults with varying glycemic and blood pressure phenotypes. International Journal of Biological and Chemical Sciences. 2010;4(6):2102-2112.

21. Isezuo S, Badung S, Omotoso A. Comparative analysis of lipid profiles among patients with type 2 diabetes mellitus, hypertension and concurrent type 2 diabetes, and hypertension: a view of metabolic syndrome. J Natl Med Assoc. 2003;95:328.

22. Sarkar D, Latif SA, Uddin MM, et al. Studies on serum lipid profile in hypertensive patient. Mymensingh Med J. 2007;16(1):70-76.
23. Aguilar-Salinas CA, Olaiz G, Valles V, et al. High prevalence of low HDL cholesterol concentrations and mixed hyperlipidemia in a Mexican nationwide survey. J Lipid Res. 2001;42(8):1298-1307.

24. Bruckert E, Baccara-Dinet M, Eschwege E. Low HDL-cholesterol is common in European type 2 diabetic patients receiving treatment for dyslipidaemia: data from a pan-European survey. Diabet Med. 2007;24(4):388-391.

25. Yusuf S, Hawken S, Ounpuu S, et al. Effect of potentially modifiable risk factors associated with myocardial infarction in 52 countries (the INTERHEART study): case-control study. Lancet. 2004;364(9438): 937-952.

26. Goyal A, Usuf S. The burden of cardiovascular disease in the Indian subcontinent. Indian J Med Res. 2006;124(3):235-244.

27. Yusuf S, Reddy S, Ônpuu S, Anand S. Global burden of cardiovascular diseases part II: variations in cardiovascular disease by specific ethnic groups and geographic regions and prevention strategies. Circulation. 2001;104:2855-2864.

28. Ghaffar A, Reddy KS, Singhi M. Burden of non-communicable diseases in South Asia. BMJ. 2004;328:807-810.

29. Zaman MM, Choudhury SR, Ahmed J, et al. Plasma lipids in a rural population of Bangladesh. Eur J Prev Cardiol. 2006;13:444-448.
Vascular Health and Risk Management

\section{Publish your work in this journal}

Vascular Health and Risk Management is an international, peerreviewed journal of therapeutics and risk management, focusing on concise rapid reporting of clinical studies on the processes involved in the maintenance of vascular health; the monitoring, prevention and treatment of vascular disease and its sequelae; and the involvement of

\section{Dovepress}

metabolic disorders, particularly diabetes. This journal is indexed on PubMed Central and MedLine. The manuscript management system is completely online and includes a very quick and fair peer-review system, which is all easy to use. Visit http://www.dovepress.com/ testimonials.php to read real quotes from published authors. 